\title{
The Ecology of Medical Care During the COVID-19 Pandemic in Japan: A Nationwide Study
}

\section{Takuya Aoki ( $\nabla$ taoki@jikei.ac.jp )}

Jikei University School of Medicine: Tokyo Jikeikai lka Daigaku https://orcid.org/0000-0002-8232-2155

Masato Matsushima

Jikei University School of Medicine: Tokyo Jikeikai Ika Daigaku

\section{Research Article}

Keywords: covid-19, delivery of health care, health behavior, japan.

Posted Date: September 27th, 2021

DOI: https://doi.org/10.21203/rs.3.rs-881846/v1

License: (c) (i) This work is licensed under a Creative Commons Attribution 4.0 International License. Read Full License 


\section{Abstract \\ Background.}

The coronavirus disease 2019 (COVID-19) pandemic has had a profound impact on health care utilization. However, the overall picture of shifts in health-seeking behaviors remains unclear.

\section{Objective.}

We assessed the ecology of medical care during the COVID-19 pandemic in Japan and compared it with the results pre-pandemic. We also investigated the associations of sociodemographic and clinical factors with health-seeking behaviors during the COVID-19 pandemic.

\section{Design and Methods.}

We conducted a nationwide cross-sectional survey of a representative sample of the general Japanese adult population in May 2021. The main outcomes were health care use for symptoms or health-related events in the last month. We assessed sociodemographic and clinical factors, including age, sex, years of education, annual household income, social isolation, and the number of chronic conditions.

\section{Key Results.}

Data were analyzed from 1,747 respondents. Over-the-counter drug use, physician's office visits, and hospital outpatient clinic visits decreased drastically during the COVID-19 pandemic compared with pre-pandemic levels. The decrease in the use of medical facilities was especially pronounced among the elderly. Sociodemographic and clinical factors were differently associated with health care utilization during the COVID-19 pandemic. Social isolation and years of education were positively associated with over-the-counter drug use, while female sex was associated with increased over-the-counter drug use and physician's office visits. In addition, the number of chronic conditions was associated with increased hospital visits.

\section{Conclusions.}

During the COVID-19 pandemic, the use of medical facilities for health-related events decreased drastically, especially among the elderly. A pharmacy is an important source of health care in a population with social isolation. These findings may be useful to researchers and policymakers in rethinking health care systems during and after the pandemic.

\section{Introduction}

The coronavirus disease 2019 (COVID-19) pandemic is considered to have had a profound impact on health care utilization worldwide. Studies conducted early during the pandemic in the US and Japan have reported that the number of physician's office visits decreased. ${ }^{1-3}$ Another study showed reductions in emergency department and inpatient utilization, as well as outpatient utilization during the early stages of the pandemic. ${ }^{4}$ These changes may 
be due to governments' implementation of various strategies such as large-scale physical distancing measures and movement restrictions. ${ }^{5}$ In Japan, the government has repeatedly declared a state of emergency, urging citizens to refrain from going out unnecessarily. ${ }^{6}$ In addition to policy factors, individuals' health-seeking behaviors may have changed during the pandemic. However, the overall picture of shifts in health-seeking behaviors due to the pandemic remains unclear.

It is useful to describe "the ecology of medical care" as a way to grasp the whole picture of health-seeking behavior. The theory of "the ecology of medical care" was first proposed by White in 1961, 7 providing a framework for understanding patterns of an individual's choices in seeking medical care for health-related events in specific populations of interest in which the number of people among the total population who had utilized medical services in a given period of time is calculated. ${ }^{8}$ This framework was replicated in different countries worldwide and offered a useful tool to researchers and health care policymakers. ${ }^{9-12}$ With a universal health coverage in Japan, the ecology of medical care has been investigated in 2003 and 2013. ${ }^{13,14}$ Compared with the 2003 study, the participants in the 2013 study were reported to have fewer physician and emergency room visits and less overthe-counter (OTC) drug use, but reported higher frequency of complementary or alternative medicine (CAM) use. $^{14}$ Thus, health-seeking behavior is changing under the influence of the social background of each era. For example, it can be inferred that social isolation, which is a state of having few social relationships or infrequent social contact with others, has had an impact on health care utilization during the pandemic.

Regarding the change in health care use due to the COVID-19 pandemic, reevaluating the ecology of medical care may be useful to researchers and policymakers in rethinking health care systems during and after the pandemic. Therefore, this study aimed to assess health-seeking behaviors for health-related events in a representative sample of the Japanese general population during the COVID-19 pandemic and to compare it with the results before the pandemic in Japan. In addition, we investigated the associations of sociodemographic and clinical factors with health-seeking behaviors during the pandemic. In particular, the interest was in the factor of social isolation, which is a major health problem and has increased globally due to the pandemic. ${ }^{15}$

\section{Methods}

\section{Design, setting, and participants}

We used the data collected from the National Usual Source of Care Survey (NUCS) conducted in May 2021. The NUCS was a nationwide mail survey that aimed to collect data on the usual source of primary care, health care use, health conditions, health-related quality of life, and sociodemographic characteristics in a representative sample of the Japanese adult population. In the NUCS, a national representative panel in Japan administered by the Nippon Research Center was used to select possible participants. This panel is composed of approximately 70,000 residents who were selected from the Japanese general population using a multistage sampling method and who participated in a previous survey from the Nippon Research Center. ${ }^{16}$ From the panel, 2,000 possible participants aged $20-75$ years were selected through stratified sampling by age, sex, and residential area. The survey participants received 500 JPY gift certificates. Among residents responding to the NUCS, eligible participants in this study were individuals who responded to the survey item regarding health care use. The institutional review board of the Jikei University School of Medicine approved this study [approval no. 32416(10505)]. 


\section{Measures}

\section{Health-seeking behaviors}

We collected data on participants' health-seeking behaviors using a structured questionnaire. Participants were asked to answer the following questions about health care use for symptoms or health-related events in the last month: OTC drug use, physician's office visit, hospital outpatient clinic visit, university medical center visit, emergency room visit, home health care use, CAM use, and hospitalization. We excluded telemedicine visits because telemedicine for new symptoms or health-related events was not widespread in Japan as of May 2021 . $^{17}$

\section{Sociodemographic and clinical factors}

We collected data on the sociodemographic and clinical factors of the participants. The questionnaire measured the age, sex, years of education, annual household income, social isolation, and the number of chronic conditions.

We used the Japanese version of the abbreviated Lubben Social Network Scale (LSNS-6) ${ }^{18}$ to assess social isolation. The LSNS- 6 score is an equally weighted sum of six items, and the scores range from 0 to 30 points, with higher scores indicating a better quality of the social network. The reliability and validity of the Japanese version of LSNS-6 have been assessed in a previous study in Japan. ${ }^{18}$ As suggested in the previous study, we classified patients with a score of $<12$ points as being socially isolated. ${ }^{19}$

We used a validated list of 20 chronic conditions that were created based on previous multimorbidity literature and relevance to the primary care population ${ }^{20}$ : hypertension, depression/anxiety, chronic musculoskeletal conditions that cause pain or limitation, arthritis/rheumatoid arthritis, osteoporosis, chronic respiratory disease (asthma, chronic obstructive pulmonary disease, or chronic bronchitis), cardiovascular disease, heart failure, stroke/transient ischemic attack, stomach problems, colon problems, chronic hepatitis, diabetes, thyroid disorder, any cancer in the past 5 years, kidney disease/failure, chronic urinary problem, dementia/Alzheimer's disease, hyperlipidemia, and obesity.

\section{Statistical analysis}

Descriptive analyses were performed using the ecology of medical care model. ${ }^{7}$ We estimated the number of persons per 1,000 residents who had experienced different health care use during a one-month period and calculated $95 \%$ confidence intervals $(\mathrm{Cl})$ for event rates.

Subgroup analyses for variables of interest in health care use were conducted by age, sex, years of education, annual household income, social isolation, and the number of chronic conditions. In addition, to investigate the associations of sociodemographic and clinical factors with each health care use, we performed multivariable logistic regression analyses. In the multivariable analyses, we defined a hospital visit as a composite outcome that included hospital outpatient clinic visits, university medical center visits, and emergency room visits.

For each analysis, we used a two-sided significance level of $P=0.05$. For missing independent variables in the regression model, we performed a complete case analysis. Statistical analyses were performed using $\mathrm{R}$ version 4.1.0 (R Foundation for Statistical Computing, Vienna, Austria; www.R-project.org).

\section{Results}




\section{Participants' characteristics}

Of the 2,000 adult residents, 1,757 responded to the NUCS (response rate: $87.9 \%$ ). Among them, we excluded 10 participants who did not respond to the survey item regarding health care use. Then, we analyzed the remaining 1,747 eligible participants. Table 1 presents the characteristics of the study population. Of the eligible participants, $22.5 \%$ were elderly ( $\geq 65$ years old), while $30.3 \%$ were considered socially isolated. Approximately half of the participants had one or more chronic conditions.

Table 1

Participants' Characteristics $(\mathrm{N}=1,747)$

\begin{tabular}{|lc|}
\hline Characteristic & $\mathrm{n}(\%)$ \\
\hline Age, $\mathrm{y}$ & $1,354(77.5)$ \\
\hline $20-64$ & $393(22.5)$ \\
\hline Gender & \\
\hline Male & $857(49.1)$ \\
\hline Female & $890(50.9)$ \\
\hline Education & \\
\hline Less than or equal to high school & $637(36.5)$ \\
\hline More than high school & $1,069(61.2)$ \\
\hline Data missing & $41(2.3)$ \\
\hline Annual household income, million JPY \\
\hline$<3.00$ ( 27,000 US dollar) & $285(16.3)$ \\
\hline $3.00-4.99$ & $526(30.1)$ \\
\hline$\geqq 5.00$ & $916(52.4)$ \\
\hline Data missing & $20(1.1)$ \\
\hline Social isolation & $790(45.2)$ \\
\hline Absent & $453(25.9)$ \\
\hline Present & $433(24.8)$ \\
\hline Data missing & $530(30.3)$ \\
\hline Number of chronic conditions & $12(0.7)$ \\
\hline 0 & \\
\hline 1 & \\
\hline$\geqq 2$ & \\
\hline Data missing & \\
\hline
\end{tabular}

Page 5/14 


\section{Ecology of medical care during the pandemic}

Table 2 shows the monthly number of health care use for symptoms or health-related events per 1,000 Japanese individuals during the COVID-19 pandemic. The most frequently used health care resources were the physicians' offices. We observed that 93 participants used an OTC drug, 113 visited a physician's office, 37 visited a hospital outpatient clinic, nine visited a university medical center, two received care in an emergency room, two received home health care, 19 visited a provider of CAM care, and 10 were hospitalized. Table 2 also shows the results of subgroup analyses by age, sex, years of education, annual household income, social isolation, and the number of chronic conditions. The frequency of OTC drug use was higher among non-elderly adults, women, those with more than high school education, those without chronic conditions, and socially isolated individuals. Moreover, women were more likely to report physician's office visits and CAM use. Elderly participants were heavier users of university medical centers and CAM and were more frequently hospitalized than non-elderly adults. In addition, participants with one or more chronic conditions were heavier users of hospital outpatient clinics, university medical centers, and CAM and were more frequently hospitalized than those without chronic conditions. 
Table 2

Ecology of Medical Care in Terms of Type of Care Stratified by Participants' Characteristics Number per 1,000 persons $(95 \% \mathrm{Cl})$

\begin{tabular}{|c|c|c|c|c|c|c|c|c|}
\hline & $\begin{array}{l}\text { OTC } \\
\text { drug } \\
\text { use }\end{array}$ & $\begin{array}{l}\text { Physician's } \\
\text { office visit }\end{array}$ & $\begin{array}{l}\text { Hospital } \\
\text { outpatient } \\
\text { clinic visit }\end{array}$ & $\begin{array}{l}\text { University } \\
\text { medical } \\
\text { center } \\
\text { visit }\end{array}$ & $\begin{array}{l}\text { Emergency } \\
\text { room visit }\end{array}$ & $\begin{array}{l}\text { Home } \\
\text { health } \\
\text { care } \\
\text { use }\end{array}$ & $\begin{array}{l}\text { CAM } \\
\text { use }\end{array}$ & Hospitalization \\
\hline Overall & $\begin{array}{l}93 \\
(80 \\
- \\
107)\end{array}$ & $\begin{array}{l}113(99- \\
129)\end{array}$ & $\begin{array}{l}37(28- \\
47)\end{array}$ & $9(5-14)$ & $2(1-6)$ & $\begin{array}{l}2(1- \\
6)\end{array}$ & $\begin{array}{l}19 \\
(14 \\
- \\
27)\end{array}$ & $10(6-16)$ \\
\hline \multicolumn{9}{|l|}{ Age } \\
\hline $20-64$ & $\begin{array}{l}104 \\
(88 \\
- \\
122)\end{array}$ & $\begin{array}{l}113(97- \\
131)\end{array}$ & $\begin{array}{l}34(25- \\
45)\end{array}$ & $7(3-13)$ & $2(0-6)$ & $\begin{array}{l}3(1- \\
8)\end{array}$ & $\begin{array}{l}17 \\
(11 \\
- \\
25)\end{array}$ & $6(3-12)$ \\
\hline$\geqq 65$ & $\begin{array}{l}53 \\
(33 \\
- \\
81)\end{array}$ & $\begin{array}{l}115(85- \\
150)\end{array}$ & $\begin{array}{l}46(27- \\
71)\end{array}$ & $\begin{array}{l}15(6- \\
33)\end{array}$ & $3(0-14)$ & $\begin{array}{l}0(0- \\
9)\end{array}$ & $\begin{array}{l}28 \\
(14 \\
- \\
50)\end{array}$ & $23(11-43)$ \\
\hline \multicolumn{9}{|l|}{ Gender } \\
\hline Male & $\begin{array}{l}81 \\
(63 \\
- \\
101)\end{array}$ & $\begin{array}{l}91(73- \\
112)\end{array}$ & $\begin{array}{l}46(33- \\
62)\end{array}$ & $7(3-15)$ & $2(0-8)$ & $\begin{array}{l}4(1- \\
10)\end{array}$ & $\begin{array}{l}13 \\
(6- \\
23)\end{array}$ & $11(5-20)$ \\
\hline Female & $\begin{array}{l}104 \\
(85 \\
- \\
126)\end{array}$ & $\begin{array}{l}134(113- \\
159)\end{array}$ & $\begin{array}{l}28(18- \\
41)\end{array}$ & $\begin{array}{l}10(5- \\
19)\end{array}$ & $2(0-8)$ & $\begin{array}{l}1(0- \\
6)\end{array}$ & $\begin{array}{l}26 \\
(16 \\
- \\
39)\end{array}$ & $9(4-18)$ \\
\hline \multicolumn{9}{|l|}{ Education } \\
\hline $\begin{array}{l}\text { Less than } \\
\text { or equal } \\
\text { to high } \\
\text { school }\end{array}$ & $\begin{array}{l}64 \\
(47 \\
- \\
86)\end{array}$ & $\begin{array}{l}126(101- \\
154)\end{array}$ & $\begin{array}{l}49(33- \\
68)\end{array}$ & $9(3-20)$ & $3(0-11)$ & $\begin{array}{l}3(0- \\
11)\end{array}$ & $\begin{array}{l}24 \\
(13 \\
- \\
39)\end{array}$ & $13(5-25)$ \\
\hline $\begin{array}{l}\text { More than } \\
\text { high } \\
\text { school }\end{array}$ & $\begin{array}{l}109 \\
(90 \\
- \\
129)\end{array}$ & $\begin{array}{l}105(87- \\
125)\end{array}$ & $\begin{array}{l}30(21- \\
42)\end{array}$ & $8(4-16)$ & $2(0-7)$ & $\begin{array}{l}2(0- \\
7)\end{array}$ & $\begin{array}{l}17 \\
(10 \\
- \\
26)\end{array}$ & $8(4-16)$ \\
\hline \multicolumn{9}{|l|}{$\begin{array}{l}\text { Annual } \\
\text { household } \\
\text { income, } \\
\text { million } \\
\text { JPY }\end{array}$} \\
\hline $\begin{array}{l}<3.00 \text { ( }= \\
27,000 \text { US } \\
\text { dollar) }\end{array}$ & $\begin{array}{l}81 \\
(52 \\
- \\
119)\end{array}$ & $\begin{array}{l}126(90- \\
171)\end{array}$ & $\begin{array}{l}28(12- \\
55)\end{array}$ & $\begin{array}{l}14(4- \\
36)\end{array}$ & $0(0-13)$ & $\begin{array}{l}0(0- \\
13)\end{array}$ & $\begin{array}{l}32 \\
(15 \\
- \\
59)\end{array}$ & $4(0-19)$ \\
\hline
\end{tabular}




\begin{tabular}{|c|c|c|c|c|c|c|c|c|}
\hline \multirow[b]{2}{*}{$3.00-4.99$} & \multicolumn{8}{|c|}{ Number per 1,000 persons $(95 \% \mathrm{Cl})$} \\
\hline & $\begin{array}{l}87 \\
(65 \\
- \\
115)\end{array}$ & $\begin{array}{l}122(95- \\
153)\end{array}$ & $\begin{array}{l}47(29- \\
67)\end{array}$ & $8(2-19)$ & $2(0-11)$ & $\begin{array}{l}0(0- \\
7)\end{array}$ & $\begin{array}{l}23 \\
(12 \\
- \\
40)\end{array}$ & $10(3-22)$ \\
\hline$\geqq 5.00$ & $\begin{array}{l}100 \\
(82 \\
- \\
122)\end{array}$ & $\begin{array}{l}104(85- \\
125)\end{array}$ & $\begin{array}{l}35(24- \\
49)\end{array}$ & $7(2-14)$ & $3(1-10)$ & $\begin{array}{l}4(1- \\
11)\end{array}$ & $\begin{array}{l}13 \\
(7- \\
23)\end{array}$ & $11(5-20)$ \\
\hline \multicolumn{9}{|l|}{$\begin{array}{l}\text { Social } \\
\text { isolation }\end{array}$} \\
\hline Absent & $\begin{array}{l}85 \\
(70 \\
- \\
103)\end{array}$ & $\begin{array}{l}116(99- \\
136)\end{array}$ & $\begin{array}{l}36(26- \\
48)\end{array}$ & $8(4-15)$ & $2(1-7)$ & $\begin{array}{l}3(1- \\
8)\end{array}$ & $\begin{array}{l}17 \\
(10 \\
- \\
26)\end{array}$ & $10(5-17)$ \\
\hline Present & $\begin{array}{l}111 \\
(86 \\
- \\
141)\end{array}$ & $\begin{array}{l}108(82- \\
137)\end{array}$ & $\begin{array}{l}40(25- \\
60)\end{array}$ & $2(0-10)$ & $2(0-10)$ & $\begin{array}{l}0(0- \\
7)\end{array}$ & $\begin{array}{l}26 \\
(15 \\
- \\
44)\end{array}$ & $9(3-22)$ \\
\hline \multicolumn{9}{|l|}{$\begin{array}{l}\text { Number } \\
\text { of chronic } \\
\text { conditions }\end{array}$} \\
\hline 0 & $\begin{array}{l}111 \\
(90 \\
- \\
135)\end{array}$ & $\begin{array}{l}97(78- \\
120)\end{array}$ & $\begin{array}{l}22(13- \\
34)\end{array}$ & $4(1-11)$ & $1(0-7)$ & $\begin{array}{l}3(3- \\
9)\end{array}$ & $\begin{array}{l}13 \\
(6- \\
23)\end{array}$ & $3(3-9)$ \\
\hline 1 & $\begin{array}{l}84 \\
(60 \\
- \\
113)\end{array}$ & $\begin{array}{l}126(97- \\
160)\end{array}$ & $\begin{array}{l}38(22- \\
59)\end{array}$ & $\begin{array}{l}13(5- \\
29)\end{array}$ & $4(1-16)$ & $\begin{array}{l}2(0- \\
12)\end{array}$ & $\begin{array}{l}18 \\
(8- \\
34)\end{array}$ & $15(6-32)$ \\
\hline$\geqq 2$ & $\begin{array}{l}67 \\
(45 \\
- \\
95)\end{array}$ & $\begin{array}{l}122(93- \\
157)\end{array}$ & $\begin{array}{l}69(47- \\
97)\end{array}$ & $\begin{array}{l}12(4- \\
27)\end{array}$ & $2(0-13)$ & $\begin{array}{l}2(0- \\
13)\end{array}$ & $\begin{array}{l}32 \\
(18 \\
- \\
54)\end{array}$ & $18(8-36)$ \\
\hline
\end{tabular}

\section{Comparison With The Pre-pandemic Study}

Figures 1 and 2 show the comparisons of the results of the present study with the ecology of medical care study conducted in Japan in 2013 before the COVID-19 pandemic. In both non-elderly and elderly groups, the present study showed lower frequencies of OTC drug use, physician's office visits, and hospital outpatient clinic visits than those in the 2013 study. Especially in the elderly group, OTC drug use decreased to approximately one-seventh, and visits to physicians' offices and hospital outpatient clinics decreased to approximately one-third.

\section{Associations Of Sociodemographic And Clinical Factors With Health-seeking Behaviors}




\section{during the pandemic}

Table 3 shows the results of multivariable logistic regression analyses, examining the associations of sociodemographic and clinical factors with health-seeking behaviors during the pandemic, including OTC drug use, physician's office visits, and hospital visits. Social isolation, female sex, and years of education were positively associated with OTC drug use. Female sex was also associated with increased number of physician's office visits. In addition, the number of chronic conditions was positively associated with hospital visits. 
Table 3

Adjusted Odds Ratio $(95 \% \mathrm{Cl})$ for Health-seeking Behaviors by Sociodemographic and Clinical Factors ( $\mathrm{N}=$ 1,747)

\begin{tabular}{|c|c|c|c|}
\hline & OTC drug use & Office visit & Hospital visit ${ }^{a}$ \\
\hline \multicolumn{4}{|l|}{ Age } \\
\hline $20-64$ & Reference & Reference & Reference \\
\hline$\geqq 65$ & $0.66(0.38-1.11)$ & $0.89(0.58-1.34)$ & $1.02(0.58-1.74)$ \\
\hline \multicolumn{4}{|l|}{ Gender } \\
\hline Male & Reference & Reference & Reference \\
\hline Female & $1.44(1.02-2.04)^{b}$ & $1.55(1.12-2.15)^{b}$ & $0.88(0.56-1.37)$ \\
\hline \multicolumn{4}{|l|}{ Education } \\
\hline Less than or equal to high school & Reference & Reference & Reference \\
\hline More than high school & $1.69(1.16-2.52)^{b}$ & $0.87(0.63-1.20)$ & $0.73(0.46-1.14)$ \\
\hline \multicolumn{4}{|c|}{ Annual household income, million JPY } \\
\hline$<3.00(\fallingdotseq 27,000$ US dollar $)$ & Reference & Reference & Reference \\
\hline $3.00-4.99$ & $1.15(0.67-2.03)$ & $1.04(0.66-1.66)$ & $1.74(0.88-3.73)$ \\
\hline$\geqq 5.00$ & $1.10(0.66-1.91)$ & $0.87(0.55-1.39)$ & $1.69(0.85-3.64)$ \\
\hline \multicolumn{4}{|l|}{ Social isolation } \\
\hline Absent & Reference & Reference & Reference \\
\hline Present & $1.49(1.03-2.13)^{b}$ & $0.92(0.64-1.29)$ & $1.10(0.67-1.76)$ \\
\hline \multicolumn{4}{|l|}{ Number of chronic conditions } \\
\hline 0 & Reference & Reference & Reference \\
\hline 1 & $0.84(0.55-1.26)$ & $1.32(0.90-1.92)$ & $2.47(1.39-4.48)^{b}$ \\
\hline$\geqq 2$ & $0.76(0.46-1.22)$ & $1.25(0.82-1.90)$ & $3.26(1.80-6.00)^{b}$ \\
\hline \multicolumn{4}{|l|}{ Abbreviations: OTC, over-the-counter. } \\
\hline \multicolumn{4}{|c|}{ ancluded hospital outpatient clinic visit, university medical center visit, and emergency room visit. } \\
\hline
\end{tabular}

\section{Discussion}

This nationwide study of the Japanese adult population revealed that OTC drug use, physician's office visits, and hospital outpatient clinic visits decreased drastically during the COVID-19 pandemic compared with the prepandemic levels. The decrease in the use of medical facilities was especially pronounced among the elderly. The present study also found that sociodemographic and clinical factors were differently associated with health- 
seeking behaviors during the pandemic. Social isolation and years of education were positively associated with OTC drug use, while female sex was associated with increased OTC drug use and physician office visits. In addition, the number of chronic conditions was associated with increased hospital visits.

Our findings were consistent with prior studies, showing a decrease in office visits during the early stages of the pandemic. $^{1-3}$ In the present study, using the ecology of medical care model, the number of visits at lower-level medical institutions such as physicians' offices and hospital outpatient clinics, where residents are mainly seen for minor health problems, decreased remarkably compared with the pre-pandemic levels. On the other hand, the number of visits at higher-level medical institutions such as university medical centers and emergency rooms, which accept patients with severe symptoms, and hospitalizations were at the same level as those before the pandemic. Although a cross-sectional survey is a common method for conducting the ecology of medical care studies, ${ }^{8,9,11}$ health care use may be underestimated compared with a health diary method, which was used in previous studies in Japan. ${ }^{13,14}$ However, the changes in health care utilization were drastic and cannot be explained by differences in the methods alone.

One of the causes of the decline in OTC drug use, physician's office visits, and hospital outpatient clinic visits may be the decreased number of common infectious diseases due to the prevention measures against the spread of infection such as hygiene and physical distancing policies. ${ }^{21,22}$ An increase in the threshold for health care use due to fear of being infected by COVID-19 at medical facilities may also have caused these results. ${ }^{3}$ Because Japanese residents tend to be more risk-averse than those in other countries, ${ }^{23}$ the risk preference for COVID-19 infection may have influenced health-seeking behaviors, especially among the elderly who are at higher risk of experiencing severe infection. In Japan, because the application and spread of telemedicine have been slow even during the pandemic, ${ }^{24}$ access to care, especially for new health-related events, is impaired in the population. Thus, it is necessary to improve access to health care by telemedicine expansion while considering the quality and safety of care and usability.

Our study also reported the association between social isolation, which is a major health problem and has increased globally due to the pandemic, and health care utilization. The health-seeking behaviors of socially isolated people during the pandemic have been unclear worldwide. The results of this study indicated that a pharmacy is an important source of health care in the population with social isolation during the pandemic. A previous study showed that social isolation was associated with negative patient experience in primary care clinics. ${ }^{25}$ Therefore, strengthening the primary care function of pharmacies as a more accessible gate opener may be effective in improving the quality of care and health outcomes in socially isolated populations. In addition, we observed that women were more likely to visit a physician's office, and patients with chronic conditions were more likely to visit a hospital. These findings were consistent with those of previous studies conducted before the

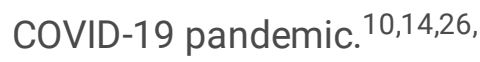

This is the first study to report the ecology of medical care in the general Japanese population during the COVID-19 pandemic. The ecology of the medical care model is a useful framework for understanding the patterns of an individual's choices in seeking medical care for health-related events. A key strength of our study is the use of data from a nationwide study, with a sample representative of the Japanese adult population, which allows for generalization of its results to the wider population. Another strength of this study is the high response rate. 
The present study has several limitations. First, the survey was retrospective, and the questions about health care utilization were asked with respect to the last month; thus, recall biases could have affected our results. Second, our data were collected during a single month, and seasonal variation of disease incidence may result in estimates that are different from the present study. Third, we used a validated list of chronic conditions; however, selfreported data for identifying chronic conditions may have introduced misclassification bias.

\section{Conclusions}

Our ecology of medical care study during the COVID-19 pandemic in Japan revealed that the use of medical facilities for health-related events decreased drastically, especially among the elderly, compared with the prepandemic levels. Moreover, a pharmacy is an important source of health care in a population with social isolation during the pandemic. These findings may be useful to researchers and policymakers in rethinking health care systems during and after the pandemic.

\section{Declarations}

\section{Acknowledgments}

Contributors: none.

Funders: This work was supported by JSPS KAKENHI Grant Number JP20K18849.

Prior presentations: none.

Conflict of Interest: Drs Aoki and Matsushima received lecture fees and lecture travel fees from the Centre for Family Medicine Development of Japanese Health and Welfare Co-operative Federation. Drs Aoki and Matsushima are advisers of the Centre for Family Medicine Development practice-based research network. Dr. Matsushima's son-in-law worked at IQVIA Services Japan K.K. which is a contract research organization and a contract sales organization. Dr. Matsushima's son-in-law works at SYNEOS HEALTH CLINICAL K.K. which is a contract research organization and a contract sales organization.

\section{References}

1. Alexander GC, Tajanlangit M, Heyward J, Mansour O, Qato DM, Stafford RS. Use and Content of Primary Care Office-Based vs Telemedicine Care Visits During the COVID-19 Pandemic in the US. JAMA Netw Open. 2020;3(10):e2021476.

2. Whaley CM, Pera MF, Cantor J, et al. Changes in Health Services Use Among Commercially Insured US Populations During the COVID-19 Pandemic. JAMA Netw Open. 2020;3(11):e2024984.

3. Takakubo, T, Odagiri, Y, Machida, M, et al. Changes in the medical treatment status of Japanese outpatients during the coronavirus disease 2019 pandemic [published online March 16, 2021]. J Gen Fam Med. doi.org/10.1002/jgf2.432.

4. Xu S, Glenn S, Sy L, et al. Impact of the COVID-19 Pandemic on Health Care Utilization in a Large Integrated Health Care System: Retrospective Cohort Study. J Med Internet Res. 2021;23(4):e26558.

5. World Health Organization. Coronavirus Disease (COVID-19): Herd Immunity, Lockdowns and COVID-19. https://www.who.int/news-room/q-a-detail/herd-immunity-lockdowns-and-covid-19. Accessed July 10, 2021. 
6. Office for Novel Coronavirus Disease Control, Cabinet Secretariat, Government of Japan. COVID-19 Information and Resources. https://corona.go.jp/en/. Accessed July 10, 2021.

7. White KL, Williams TF, Greenberg BG. The ecology of medical care. N Engl J Med. 1961;265:885-892.

8. Green LA, Fryer GE Jr, Yawn BP, Lanier D, Dovey SM. The ecology of medical care revisited. N Engl J Med. 2001;344(26):2021-2025.

9. Johansen ME, Richardson CR. The Ecology of Medical Care Before and After the Affordable Care Act: Trends From 2002 to 2016. Ann Fam Med. 2019;17(6):526-537.

10. Ferro A, Kristiansson PM. Ecology of medical care in a publicly funded health care system: a registry study in Sweden. Scand J Prim Health Care. 2011;29(3):187-192.

11. Xiong X, Cao X, Luo L. The ecology of medical care in Shanghai. BMC Health Serv Res. 2021;21(1):51.

12. Shao CC, Chang CP, Chou LF, Chen TJ, Hwang SJ. The ecology of medical care in Taiwan. J Chin Med Assoc. 2011;74(9):408-12.

13. Fukui T, Rhaman M, Takahashi O, et al. The ecology of medical Care in Japan. JMAJ. 2005;48(4):163-167.

14. Fukui T, Rahman M, Ohde S, Hoshino E, Kimura T, Urayama KY, Omata F, Deshpande GA, Takahashi $O$. Reassessing the Ecology of Medical Care in Japan. J Community Health. 2017;42(5):935-941.

15. Wu B. Social isolation and loneliness among older adults in the context of COVID-19: a global challenge. Glob Health Res Policy. 2020;5:27.

16. Nippon Research Center. Nippon Research Center. https://www.nrc.co.jp/english/index.html. Accessed June 2, 2021.

17. Ministry of Health, Labour and Welfare. The 15th study group on the review of guidelines for the appropriate implementation of telemedicine. https://www.mhlw.go.jp/content/10803000/000786235.pdf. Accessed June $2,2021$.

18. Kurimoto A, Awata S, Ohkubo T, et al. Reliability and validity of the Japanese version of the abbreviated Lubben Social Network Scale. Nihon Ronen Igakkai Zasshi. 2011;48(2):149-157.

19. Lubben J, Blozik E, Gillmann G, et al. Performance of an abbreviated version of the Lubben Social Network Scale among three European community-dwelling older adult populations. Gerontologist. 2006;46(4):503513.

20. Fortin M, Almirall J, Nicholson K. Development of a research tool to document self-reported chronic conditions in primary care. J Comorb. 2017;7(1):117-123.

21. Fricke LM, Glöckner S, Dreier M, Lange B. Impact of non-pharmaceutical interventions targeted at COVID-19 pandemic on influenza burden - a systematic review. J Infect. 2021 Jan;82(1):1-35.

22. Lee HH, Lin SH. Effects of COVID-19 Prevention Measures on Other Common Infections, Taiwan. Emerg Infect Dis. 2020;26(10):2509-2511.

23. Canale N, Vieno A, Lenzi M, Griffiths MD, Perkins DD, Santinello M. Cross-national differences in risk preference and individual deprivation: a large-scale empirical study. Personality and Individual Differences, 2018;126:52-60.

24. Miyawaki A, Tabuchi T, Ong MK, Tsugawa Y. Age and Social Disparities in the Use of Telemedicine During the COVID-19 Pandemic in Japan: Cross-sectional Study. J Med Internet Res. 2021;23(7):e27982.

25. Aoki T, Yamamoto Y, Ikenoue T, et al. Social Isolation and Patient Experience in Older Adults. Ann Fam Med. 2018;16(5):393-398. 
26. Glynn LG, Valderas JM, Healy P, et al. The prevalence of multimorbidity in primary care and its effect on health care utilization and cost. Fam Pract. 2011;28(5):516-23.

\section{Figures}

2013

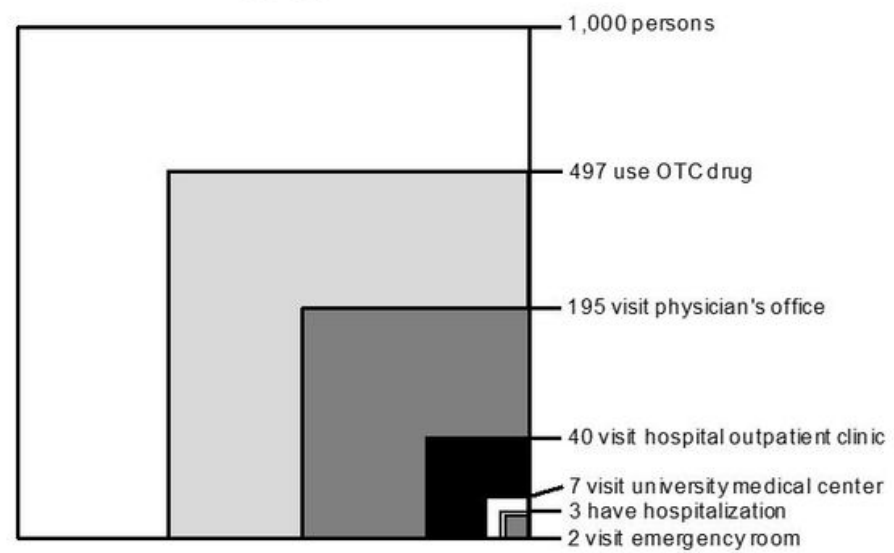

2021

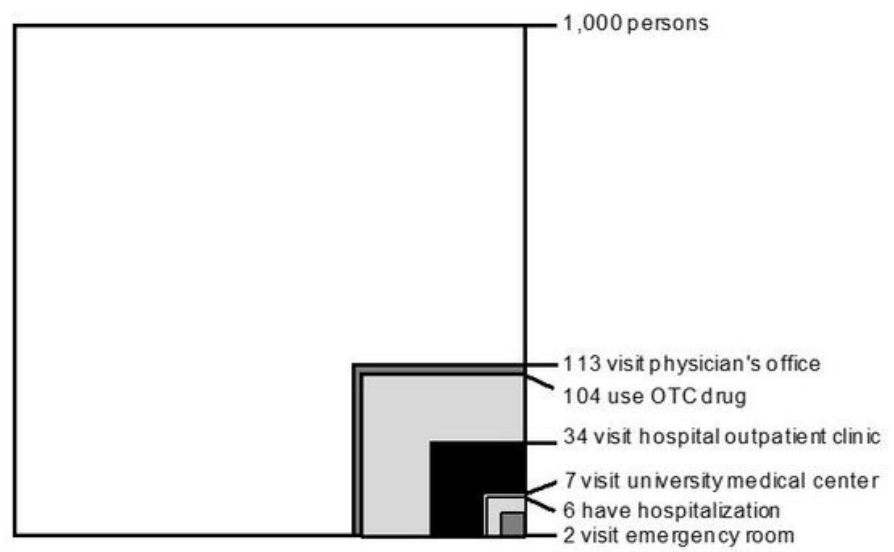

Figure 1

Comparison of Health-seeking Behaviors Among Non-elderly Adults (< 65 years old) Between the Previous Study in 201314 and the Present Study in 2021

2013

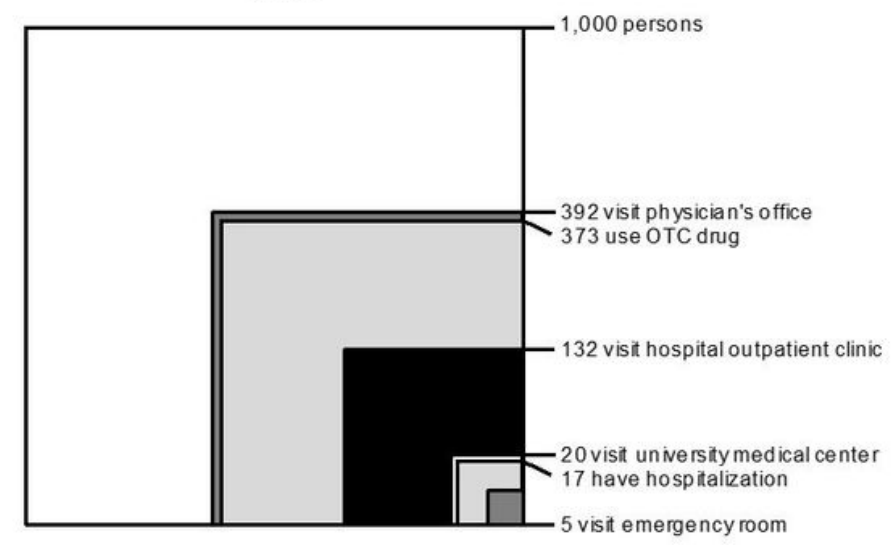

\section{1}

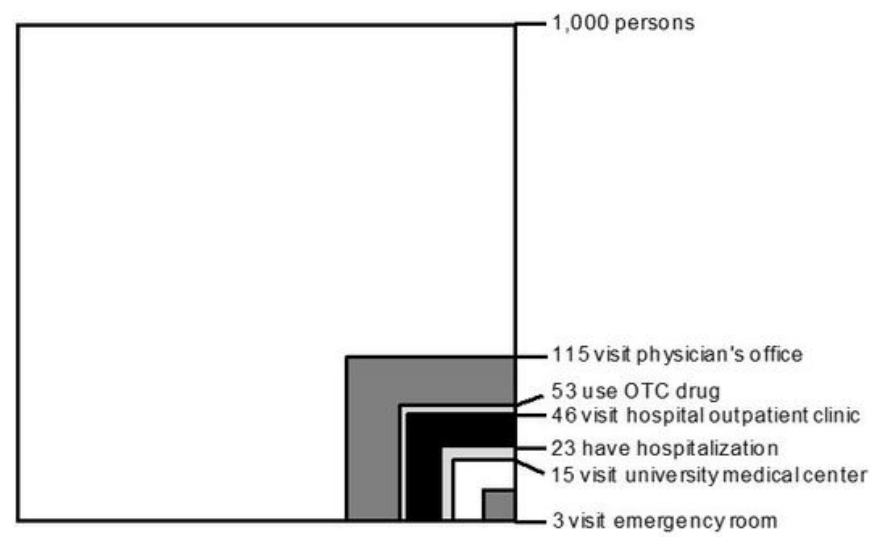

\section{Figure 2}

Comparison of Health-seeking Behaviors Among Elderly ( $\geq 65$ years old) Between the Previous Study in 201314 and the Present Study in 2021 